\title{
O DESCOMPROMISSO ONTOLÓGICO DA CIÊNCIA MODERNA E SUAS RAÍZES MEDIEVAIS
}

Carlos Arthur R. Nascimento*

SÍNTESE - Tomás de Aquino ou Roberto Grosseteste não podiam prever a importância que a ciência matematizada da natureza assumiria a partir do século XVII. Eles, no entanto, não contestam a possibilidade de um conhecimento da natureza baseado em seus aspectos quantitativos e não na essência das substâncias naturais. Eles reservam um lugar para este tipo de ciência e o justificam. Quanto a Tomás, é preciso ainda lembrar que, embora para ele o objeto próprio proporcionado de nosso intelecto seja a essência das coisas materiais, não conhecemos as diferenças especificas nem das substâncias materiais nem das espirituais. Donde termos de nos contentar com descrições no que se refere às substâncias materiais e só podermos conhecer as espirituais por causalidade, ultrapassamento e remoção.

PALAVRAS-CHAVE - Aquino. Essência. Matematização. Grosseteste. Ciência.
ABSTRACT - Neither Thomas Aquinas nor Roberto Grosseteste could foresee the importance accorded to the mathematized science of nature in the seventeenth century and after. And yet they did not contest the possibility of a knowledge of nature based on its quantitative aspects, as opposed to the essence of natural substances. They made room for this type of science and justified it. As for Aquinas, it is also important to recall that, although holding the proper proportionate object of our intellect to be the essence of material things, we do not know the specific differences of either material or spiritual substances. We must, therefore, content ourselves with descriptions as far as material substances are concerned, and we can only know spiritual substances through causality, overcoming, and removal.

KEY WORDS - Aquinas. Essence. Mathematization. Grosseteste. Science.

Em sua ainda recente encíclica sobre $A$ fé e a razão, o papa João Paulo II refere-se várias vezes a uma filosofia do ser (cf., por exemplo, os números $4,5,44$, 68) culminando com a recomendação de uma "filosofia do ser" cuja "força e perenidade derivam do fato de se basear precisamente sobre o ato de ser" (no. 97). ${ }^{1}$ Para além da crítica do fenomenismo, do relativismo, do historicismo ou do positivismo, talvez se possa ver nesta preocupação um certo mal-estar diante de uma ciência que se detém nos fenômenos, não pretendendo pronunciar-se sobre o que

* UNICAMP - Universidade Estadual de Campinas.

1 Utilizamos a tradução brasileira feita pelas Ed. Paulinas, São Paulo, 1998, Coleção "A voz do Papa", $\mathrm{n}^{\circ} 160$.

v. 44

n. 3

Setembro 1999

p. $649-658$ 
as coisas são ou não são. Situação esta que poderia parecer um tanto paradoxal, uma vez que, nos inícios da ciência moderna, o que constituiu problema aos olhos da Igreja Católica foi justamente a pretensão realista, sobretudo de Galileu. O que a Igreja, por intermédio do Cardeal Bellarmino, recomendava era justamente uma postura operacionalista ou instrumentalista, que considerasse as hipóteses astronômicas, não como tradução do ser das coisas, mas pura e simplesmente como artifícios de que os astrônomos se serviriam para correlacionar dados de observação, nada dizendo sobre como as coisas são em si mesmas. ${ }^{2}$

Neste contexto não seria destituído de interesse chamar a atenção para três pontos: um primeiro ligado com a maneira como Tomás de Aquino concebe 0 trabalho da elaboração teológica; o segundo referente ao seu realismo; o terceiro mais especificamente relacionado com seu modo de situar o conhecimento matematizado da natureza.

Quanto ao primeiro tópico, parece-nos que ainda não se explorou suficientemente uma conhecida passagem da Suma de teologia de Tomás de Aquino, acerca da Trindade divina. Trata-se da resposta ao segundo argumento do artigo primeiro da questão 32 da Ia parte da referida Suma. O argumento em questão pretende que é possível conhecer a Trindade das pessoas em Deus pela razão natural: "Além disso, Ricardo de São Vitor diz no livro Sobre a Trindade - 'Creio, sem dúvida, que não faltem para qualquer explicação da verdade, não apenas argumentos prováveis, mas até mesmo necessários'. Donde, mesmo para provar a Trindade das pessoas, alguns aduzirem uma razão a partir da infinitude da bondade divina, que se comunica infinitamente na processão das pessoas divinas. Outros, porém, pelo fato de que 'não pode haver posse agradável de nenhum bem sem partilha'. Agostinho, por sua vez, procede à manifestação da Trindade das pessoas a partir da processão do verbo e do amor na nossa mente, caminho que seguimos acima (O. 27, a. 1 e 3). Logo, a Trindade das pessoas pode ser conhecida pela razão natural". $\mathrm{Na}$ resposta a este argumento, Tomás retoma o procedimento típico da astronomia antiga, resumido por Geminos (séc. I a.C.) e transmitido por Simplício (527-565): ${ }^{3}$

2 Ver a conhecida carta do cardeal Bellarmino ao carmelita Paulo Antônio Foscarini. Tradução brasileira em G. Galilei, Ciência e fé, Cartas de Galileu sobre a questão religiosa. S. Paulo: Nova Stella, 1988, p. 105-107.

3 O texto de Geminos é citado por P. Duhem, Salvar os fenômenos. Campinas: Cademos de Histónia e Filosofia da Ciência, Suplemento 3/ 1984, Centro de Lógica, Epistemologia e História da Ciência, p. 11-12. Simplício reproduz esta passagem ao comentar a Física de Aristóteles, Liv. II, cap. 2, onde este trata da distinção entre a física e a matemática. Refere-se também a Geminos ao comentar o tratado Do céu. Restaria precisar como Tomás de Aquino tomou conhecimento da distinção entre os dois tipos de prova a que ele se refere. Seu comentário à Física parece revelar pouco conhecimento do comentário de Simplício (cf. L. Elders, Autour de Saint Thomas d'Aquin. Paris: FACÉditions Brugge: Uitgeverij TABOR, 1987, v. 1, p. 27-28). Por outro lado, Tomás conheceu bem o comentário ao tratado Do céu por Simplicio, através da tradução de Moerbeke (datada de 15/06/1271), como o seu próprio comentário o testemunha. Mas, tanto o comentário da Física como do tratado Do céu por Tomás de Aquino são posteriores à la parte de sua Suma de teologia. 
"Ao segundo argumento deve dizer-se que aduz-se uma razão para alguma coisa de dois modos. De um modo, para provar suficientemente algum fundamento, assim como na ciência da natureza aduz-se uma razão suficiente para provar que o movimento do céu é sempre de velocidade uniforme. De outro modo, aduz-se uma razão, não que prove suficientemente o fundamento, mas que mostre que os efeitos conseqüentes concordam com o fundamento já estabelecido, assim como na astronomia estabelece-se a razão dos excêntricos e dos epiciclos pelo fato de que, estabelecido isto, podem ser salvas as aparências sensíveis acerca dos movimentos celestes. No entanto, esta razão não é suficientemente probante, porque, talvez estabelecido também algo diferente, poderiam ser salvas. Portanto, do primeiro modo, pode ser aduzida uma razão para provar que Deus é uno e similares. Mas, apresenta-se do segundo modo a rảzão que é aduzida para manifestar a Trindade. Pois, tais razões são concordes com a Trindade já estabelecida; não, porém, de modo que a Trindade das pessoas seja provada por estas razões. - Isto é patente em cada uma delas. Com efeito, a bondade infinita de Deus manifesta-se também na produção das criaturas porque cabe à força infinita produzir do nada. Com efeito, não é preciso que, se a bondade infinita se comunica, algo de infinito proceda de Deus, mas que receba a bondade divina de acordo com o seu modo. - Igualmente, também o que se diz que 'sem partilha não pode haver posse agradável de nenhum bem' tem lugar quando numa pessoa não se encontra a bondade perfeita donde, precisar, para a bondade plena, da alegria no bem de algum outro a si associado. - Por outro lado, a semelhança do nosso intelecto não prova suficientemente algo de Deus, pelo fato de que o intelecto não se encontra univocamente em Deus e em nós. Daí vem que Agostinho, nos Tratados sobre o Evangelho de São João, diz que, pela fé se chega ao conhecimento e não ao contrário."

Os comentários deste texto costumam se deter na distinção entre os preâmbulos da fé (por exemplo, que há Deus e que ele é único) e os artigos de fé propriamente ditos (a Trindade, por exemplo). Quanto aos primeiros, podem ser aduzidos argumentos suficientemente probantes; quanto aos segundos, não. Podem apenas ser invocados argumentos que manifestam de algum modo os artigos de fé, sem serem suficientemente probantes. Seria, talvez, possível ir um pouco além e sustentar que a razão teológica nada diz sobre a realidade divina; que ela apenas expressa esta realidade para nós, de um modo que nos seja aceitável. Assim como os excêntricos e os epiciclos nos permitem lidar com os movimentos dos planetas sem que tenhamos necessidade de sustentar sua existência na natureza, assim também falar do Verbo de Deus é um modo de exprimir para nós a segunda pessoa da Trindade, sem que haja em Deus algo como o nosso verbo mental. Ou melhor dizendo: a teoria do verbo mental humano aponta numa certa direção, no que se refere à segunda pessoa da Trindade, sem que nos dê nenhuma apreensão do que é a realidade divina, permanecendo esta inacessivel à mente humana: "sicut ignoto conjungitur" (Dionísio, Teologia mística, I, 3; cf. Ia, q. 84, a.5, arg. 1).

Aliás, e com isto passamos ao segundo ponto, para Tomás não é apenas na natureza ou essência de Deus ou das substâncias espirituais que nos permanece oculta. Mesmo no domínio do objeto próprio proporcionado do intelecto humano, a natureza das coisas sensiveis, não temos conhecimento das diferenças especificas, o que impede a formulação de definições essenciais, devendo nos contentar com descrições, em que as propriedades são utilizadas no lugar das diferenças essenciais. Basta citar uma conhecida passagem de $O$ ente $e$ a essência: 
"Visto que nestas substâncias [isto é, nas substâncias imateriais] a qüididade não é o mesmo que o ser, por isso são ordenáveis no predicamento [da substância]; e, por isso, encontram-se nelas gênero, espécie e diferença, embora suas diferenças próprias nos sejam ocultas. De fato, também nas coisas sensiveis, as próprias diferenças essenciais nos são desconhecidas; donde, serem significadas por diferenças acidentais que se originam das essenciais, assim como a causa é significada pelo seu efeito, assim como bípede é posto como diferença do homem. Ora, os acidentes próprios das substâncias imateriais nos são desconhecidos; donde, suas diferenças não poderem ser por nós significadas, nem por si, nem pelas diferenças acidentais." ${ }^{\text {" }}$

Assim sendo, Tomás afirma simultaneamente que o intelecto humano visa a essência das coisas materiais, sem no entanto apreendê-la diretamente; com a possível exceção do próprio ente humano, único acerca do qual dispomos de uma definição essencial: "animal racional".

Tomás conhecia também - e este é o nosso terceiro ponto - um certo número de disciplinas, por ele chamadas de "ciências intermediárias", que foram as protagonistas da revolução científica do século XVII. Estas disciplinas não demonstram com base na definição essencial do seu subjectum, mas tendo em conta o aspecto quantificável deste; é o que constitui sua força e seus limites. ${ }^{6}$ Roberto Grosseteste, provavelmente uma das fontes de Tomás em sua teoria do subjectum das ciências intermediárias em sua forma mais elaborada," deixa também perfeitamente claro que a demonstração da ciência matematizada da natureza não se baseia na essência ou natureza das coisas. Seu exemplo, tirado da radiação luminosa, mostra claramente como se estruturam os dois tipos de demonstração: um aplicando um teorema de semelhança de triângulos e outro recorrendo ao axioma da regularidade da natureza, entendido como uma lei ontológica. O segundo tipo de demonstração (o que seria construído a partir da natureza da coisa) faz ainda intervir entidades cujo estatuto seria difícil determinar como o "úmido espiritual".

Os medievais, como Grosseteste ou Tomás de Aquino, não podiam prever que as "ciências intermediárias" iriam açambarcar praticamente todo o domínio da ciência da natureza (física) a partir da revolução galileana. O que parece certo, porém, é que eles não parecem de modo nenhum contestar a legitimidade de um conhecimento que não se ocupa com as essências e sim com as propriedades e os sintomas. Sua teoria da ciência parece prever um lugar para este tipo de ciência e legitimá-lo.

4 Tomás de Aquino, $O$ ente e a essência. Petrópolis: Vozes, 1995, Ed. bilíngue, cap. 5, no 67, p. 4647. Outras referências em R. Gosselin, Le De ente et essentia de S. Thomas d'Aquin. Paris: Vrin, 1948 , p. 40 , n. 2.

5 Cf. Carlos Arthur R. do Nascimento, "O caminho intermediário: alguns limites do conhecimento intelectual humano, segundo Tomás de Aquino". Trans/Form/Ação (S. Paulo), v. 19, p. 207-208, 1996.

Cf. Carlos Arthur R. do Nascimento, De Tomás de Aquino a Galileu. Campinas: IFCH, UNICAMP, 1998 , 2. ed., p. $66,70-71$.

7 No seu comentário aos Segundos analíticos (I, 25) Tomás de Aquino se valeria (de acordo com R.-A. Gauthier, editor da edição revista da Leonina, Tomo I, 2, p. 90), entre outros, de Grosseteste (cf. comentário aos Segundos analíticos I, 12). Ver também Anexo I.

Cf. Anexo II: 


\section{ANEXO I}

TOMAS DE AQUINO - Exposição sobre os "Segundos Analíticos" de Aristóteles, Livro I, lição 25.

(1) De outro modo, porém, difere etc. depois que o Filósofo mostrou como a demonstração do quê difere da demonstração do porquê na mesma ciência, mostra aqui como diferem em ciências diversas.

A tal respeito faz duas coisas. Primeiro propõe o que pretende, dizendo que 0 porquê difere do quê de um modo distinto dos já tratados, pelo fato de que são considerados em ciências distintas, isto é, que a uma ciência pertence saber 0 porquê e a outra ciência pertence saber quê.

Em segundo lugar, quando diz Tais são etc. manifesta o proposto. E a tal respeito faz duas coisas: primeiro manifesta o proposto nas ciências em que uma está sob a outra; em segundo lugar nas ciências em que uma não está sob a outra quando diz: Enfim, muitas ciências que não são subordinadas, etc.

A respeito do primeiro, faz duas coisas: primeiro mostra como se comportam entre si as ciências das quais uma está sob a outra, a uma das quais pertence 0 porquê e à outra o quê; em segundo lugar mostra como nas precitadas ciências, o porquê pertence a uma delas e o quê a outra, quando diz: Aqui, com efeito, o conhecimento do quê etc. A respeito do primeiro faz duas coisas: primeiro mostra como as supracitadas ciências se comportam entre si segundo a ordem; em segundo lugar, mostra como se comportam entre si segundo a concordância, quando diz: Certas destas ciências são quase univocas etc.

(2) Diz, portanto, em primeiro lugar que tais ciências (isto é, aquelas a uma das quais pertence o quê e à outra o porquê) são todas aquelas que se comportam de tal maneira entre si que uma está sob uma outra. Ora, é preciso entender que uma ciência está sob uma outra de duas maneiras. De um primeiro modo, quando o "sujeito" de uma ciência é uma espécie do "sujeito" da ciência superior, assim como o animal é uma espécie do corpo natural e por isso a ciência dos animais está sob a ciência natural. De outro modo, quando o "sujeito" da ciência inferior não é uma espécie do "sujeito" da ciência superior, mas o "sujeito" da ciência inferior se compara ao "sujeito" da superior como o material em relação ao formal.

E é desta maneira que Aristóteles considera aqui que uma ciência está sob uma outra, assim como a especulativa, isto é, a perspectiva se comporta em relação à geometria. Com efeito, a geometria trata da linha e das outras extensões, a perspectiva, porém, trata da linha determinada a uma matéria, isto é, da linha visual. Ora, a linha visual não é uma espécie da linha pura a simples, assim como o triângulo de madeira não é uma espécie do triângulo. Com efeito, ser de madeira não é uma diferença do triângulo. A mecânica, isto é, a ciência da fabricação de máquinas e engenhos, comporta-se de maneira semelhante para com a estereometria, isto é, a ciência que trata das mensurações dos corpos. E diz-se que esta ciência está sob uma ciência, pela aplicação do formal ao material. Pois as medidas dos corpos pura e simplesmente comparam-se às medidas das madeiras e dos 
outros materiais requeridos para as máquinas e engenhos por aplicação do formal ao material. E a harmônica, isto é, a música, comporta-se de maneira semelhante para com a aritmética Pois a música aplica o número formal (que 0 aritmético considera) à matéria, isto é, aos sons.

Comporta-se de maneira semelhante à aparência, isto é, a ciência naval que considera os sinais aparentes de calmaria ou de tempestade, para com a astronomia, que considera os movimentos e as posições dos astros.

(3) Depois, quando diz: Certas destas ciências são quase unívocas etc., mostra como se comportam entre si as precitadas ciências segundo a concordância, dizendo que tais ciências são quase unívocas entre si. Diz "quase" porque concordam no nome do gênero e não no nome da espécie. Com efeito todas as precitadas ciências são chamadas de matemáticas; algumas porque tratam de um "sujeito" abstraído da matéria, como a geometria e aritmética, que são pura e simplesmente matemáticas; outras por aplicação dos princípios matemáticos às coisas materiais, assim como a astronomia é chamada de matemática e também a ciência naval, e igualmente a harmônica, isto é, a música é chamada de matemática e também a que procede segundo o ouvido, isto é, a prática da música, que conhece os sons pela experiência do ouvido. Ou pode dizer-se que são univocas, porque concordam até no nome da espécie. Pois a (ciência) naval é chamada de astronomia e a prática da música é chamada de música. Diz, porém "quase" porque tal não acontece em todas (estas ciências) mas em várias.

(4) Depois quando diz: Aqui, com efeito, o conhecimento do quê etc., manifesta, como nas precitadas ciências, a uma delas pertence o quê e à outra o porquê. A este respeito faz duas coisas: primeiro, mostra como cabe às ciências que contêm outras sob si dizer o porquê; em segundo lugar, como cabe às ciências que estão contidas sob elas dizer o porquê a respeito de outras ciências, quando diz: Está porém para a perspectiva assim como esta etc. Deve, portanto, saber-se a respeito do primeiro que em todas as ciências supracitadas, aquelas que estão contidas sob outras aplicam os princípios matemáticos ao sensivel. Aquelas porém que contêm sob si as outras são mais matemáticas Por isso o Filósofo diz primeiro que cabe aos sensiveis, isto é, às ciências inferiores que aplicam ao sensivel conhecer o quê, mas saber o porquê cabe aos matemáticos, isto é, às ciências cujos princípios são aplicados ao sensivel. Cabe a estas, com efeito, demonstrar o que é assumido como causa nas ciências inferiores. E como alguém poderia crer que quem conhecesse o porquê, necessariamente conheceria também o quê, remove isto em seguida, dizendo que muitas vezes os que sabem o porquê ignoram o quê. Manifesta isto por meio de um exemplo: os que consideram o universal, muitas vezes ignoram certos singulares pelo fato de não aplicarem-se pela consideração; assim como o que sabe que toda mula é estéril, ignora-o a respeito desta mula particular que não toma em consideração. De maneira semelhante o matemático que demonstra o porquê, ignora às vezes o quê, pois não aplica os princípios da ciência superior ao que é demonstrado na ciência inferior. 
E porque dissera que saber o porquê cabe aos matemáticos, quer mostrar qual o gênero de causa que é assumido pelos matemáticos. Donde dizer que estas ciências que recebem o porquê das matemáticas são algo de diferente, isto é, diferem destas segundo o "sujeito", isto é, enquanto aplicam à matéria Donde, tais ciências usarem das espécies, isto é, dos princípios formais que recebem das matemáticas. Com efeito, as ciências matemáticas tratam das espécies. Pois, sua consideração não diz respeito ao sujeito, isto é, à matéria. Pois, embora aquilo que a geometria considera exista na matéria, como a linha, a superfície e coisas semelhantes, no entanto, a geometria não as considera enquanto existem na matéria, mas enquanto são abstratos. Pois a geometria abstrai da matéria segundo a consideração, aquilo que existe na matéria segundo o ser. As ciências a ela subaltemadas, porém, ao contrário, tomam o que é considerado abstratamente pelo geômetra, e aplicam à matéria. Donde ser patente que a geometria diz o porquê nestas ciências segundo a causa formal.

(5) Depois quando diz: Está porém para a perspectiva assim como esta etc., mostra que também a ciência subalternada diz o porquê, não a respeito da subalternante, mas a respeito de uma certa outra. De fato, a perspectiva é subalternada à geometria $\mathrm{E}$ se compararmos a perspectiva com a geometria, a perspectiva diz, o quê e a geometria o porquê. Mas, assim como a perspectiva é subalternada à geometria, assim também a ciência do arco-íns é subalternada à perspectiva De fato, aplica os princípios tratados pura e simplesmente pela perspectiva, a uma matéria determinada. Donde, competir ao físico que trata do arco-íris conhecer o quê, mas ao perspectivo compete saber o porquê. Com efeito o físico diz que a orientação da vista para uma nuvem disposta de certo modo em relação ao sol é a causa do arco-íris. Mas o porquê ele o toma do perspectivo.

(6) Depois quando diz: Enfim muitas ciências que não são subordinadas etc., mostra como o quê e o porquê diferem em ciências diversas não subalternadas, dizendo que muitas ciências que não são subordinadas entre si, comportam-se uma em relação à outra deste modo, isto é, cabendo a uma o quê e à outra o porquê. Como é patente da medicina e da geometria. Com efeito o "sujeito" da medicina não é incluído sob o "sujeito" da geometria como o "sujeito" da perspectiva; no entanto, os princípios da geometria são aplicáveis a alguma conclusão considerada na medicina Por exemplo, que as feridas circulares se curem mais lentamente. A esse respeito, saber o quê compete ao médico que o experimenta, mas saber o porquê cabe ao geômetra a quem compete conhecer que o círculo é uma figura sem ângulo; donde as partes da ferida circular não se aproximarem de tal modo que possam unir-se facilmente. Deve, ainda, saber-se que esta diferença do quê e do porquê que se dá segundo ciências diversas, está contida sob um dos modos supracitados, isto é, quando se faz uma demonstração pela causa remota. 


\section{ANEXO II}

ROBERTO GROSSETESTE, Comentánio sobre os livros dos Analíticos Posteriores, Ed. P. Rossi, Florença: Leo S. Olschki Ed., 1981, Liv. I, cap.8.

A $11^{\text {a }}$ conclusão desta ciência é a seguinte: nem tudo que é silogizado a partir de (premissas) verdadeiras, indemonstráveis e imediatas é sabido ou demonstrado e a razão disto é que na demonstração o primeiro (termo) é dito do médio e o médio do terceiro de acordo com o que ele próprio é. Ora, é possivel construir um silogismo a partir de (premissas) verdadeiras, indemonstráveis e imediatas e, no entanto, o primeiro (termo) não ser dito do médio, nem o médio do terceiro de acordo com o que ele próprio é, como foi o silogismo de Brísson. De fato, o médio no seu silogismo foi comum e não apropriado à sua conclusão; donde sua demonstração poder convir também em outros gêneros e foi mostrado antes que a demonstração não convém em outro gênero, pois é necessário que o médio e os extremos estejam na mesma proximidade.

Ora, o silogismo de Brísson é o seguinte. O círculo é maior que toda figura retilínea inscrita no círculo e menor que toda figura retilínea circunscrita ao círculo, igualmente o quadrado igual ao triângulo retângulo do qual um lado dos que contêm o ângulo reto é igual ao semidiâmetro do círculo e o outro é igual à circunferência do círculo é maior que toda figura retilinea inscrita no círculo e menor que toda figura retilínea circunscrita. Ora, quaisquer que sejam maiores e menores em relação aos mesmos, são iguais entre si; logo, o círculo e o quadrado são iguais.

Este silogismo, embora seja a partir de premissas verdadeiras, indemonstráveis e imediatas não é demonstrativo, pois pelo mesmo (termo) médio pode ser provado de muitos outros que eles são iguais, com efeito, convém a todos dois que sejam iguais, o serem maiores e menores em relação aos mesmos. Ordena-se, então, o sentido da letra (do texto) como segue. Visto ser manifesto que nem tudo é demonstrado, mas que o que é demonstrado é mostrado a partir dos princípios e, visto o que é demonstrado ser por si e de acordo com o que ele próprio é, visto, digo, assim ser, algo não é sabido, embora seja mostrado a partir de (premissas) verdadeiras, indemonstráveis e imediatas, pois acontece demonstrar a partir de tais (premissas) assim como Brísson demonstrou o tetragonismo e, no entanto, não será uma verdadeira demonstração, pois o médio será o comum que estará em outros sujeitos não próximos e primeiros, assim como inere ao sujeito proposto, não como próximo e por primeiro; ora, o que conhece por um (termo) médio que inere ao sujeito não por primeiro não sabe senão de acordo com o acidente, pois o (termo) médio pelo qual sabe-se verdadeiramente não convém em outro gênero a ser demonstrado. Ora, é sabido de acordo com 0 acidente o que quer que não é sabido a partir dos princípios próprios, assim como ter três ângulos iguais a dois retos, como inira por si àquilo do que é provado, é mostrado a partir dos princípios próprios pelo fato de que a afecção provada inere sempre por si e na medida em que o próprio (termo) médio tem necessariamente de estar numa proximidade semelhante para com ambas as extremidades, de modo que o primeiro inira ao médio por si e por primeiro e o médio ao terceiro por si e por primeiro. Se, 
no entanto, o médio e os extremos não estiverem na proximidade mencionada, então o médio é de uma ciência superior subalternante e os extremos são de uma ciência subalternada, assim como uma conclusão música é provada por um médio aritmético; no entanto, quando o médio aritmético é posto num silogismo que demonstra uma conclusão música, está na mesma proximidade com os extremos. Isto Aristóteles diz neste trecho do texto: "As que são deste tipo são demonstradas de maneira semelhante" (I, 9, 76 a 10-11), isto é, tais conclusões da ciência subalternada são demonstradas de maneira semelhante, isto é, por um (termo) médio aproximado dos extremos. Cumpre, com efeito, saber que o médio que é da ciência superior, considerado em si, está na mesma proximidade com os extremos da ciência superior; como os extremos da ciência superior são superiores e mais comuns do que os extremos da ciência inferior, o médio da ciência superior tomado tal qual ele próprio é na ciência superior não pode estar na proximidade mencionada para com os extremos da ciência inferior, de modo que o primeiro (termo) seja dito dele e ele do terceiro na medida em que é ele próprio e por primeiro. No entanto, como o sujeito da ciência subalternada tem em si o sujeito da ciência subalternante com uma condição acrescentada que o apropria à subalternada, assim o médio tomado da ciência subalternante, quando vem no silogismo que demonstra uma conclusão da ciência subalternada, recebe sobre si as condições pelas quais é apropriado à ciência subalternada e o próprio médio tal qual está no silogismo que demonstra a conclusão da ciência subalternada está na proximidade supracitada com os extremos desta ciência, e é dito do terceiro na medida em que é ele próprio e o primeiro (é dito) igualmente do próprio médio na medida em que é ele próprio. Portanto, tanto o primeiro como o médio, que são tomados da ciência superior, quando vêm na ciência inferior, são apropriados ao sujeito desta ciência inferior; para que isto seja mais evidente apresento um exemplo disto.

"Demonstra-se na perspectiva que todos dois ângulos, dos quais um é constituído pelo raio incidente com o espelho e o outro pelo raio refletido, são dois ângulos iguais. Tal conclusão é provada por esta da geometria: de todos dois triângulos, dos quais um ângulo de um é igual a um ângulo do outro, e os lados que compreendem os ângulos iguais são proporcionais, os ângulos restantes, enquanto correspondentes, são iguais. Esta proposição, na medida em que é pura e simplesmente geométrica, abstrai dos triângulos, ângulos e lados radiantes. Mas, na medida em que aparece no silogismo que demonstra a supracitada conclusão da ciência dos espelhos é apropriada aos triângulos, ângulos e lados radiantes, da seguinte maneira: de todos os dois triângulos radiantes dos quais um angulo radiante de um é igual a um angulo radiante do outro, e os lados radiantes que compreendem os ângulos radiantes são proporcionais, os ângulos radiantes restantes, enquanto correspondentes são iguais. Ora, todos dois ângulos, dos quais um é constituído pelo raio incidente com o espelho e o outro pelo raio refletido, são dois ângulos radiantes correspondentes de dois triângulos radiantes, dos quais um ângulo radiante de um é igual a um angulo radiante do outro e os lados radiantes que compreendem os ângulos radiantes iguais são proporcionais. Logo, todos dois ângulos dos quais um é constituido pelo raio incidente com o espelho e o outro pelo raio refletido, são dois ângulos radiantes iguais. É, pois, manifesto, que tanto na ciência subalternada quanto na ciência subalternante o termo médio utilizado, tal 
como está no silogismo, é próximo dos termos extremos. No entanto, o silogismo da ciência inferior difere do silogismo da superior no seguinte: o silogismo da ciência inferior é um silogismo de quê, mas o silogismo da ciência superior é um silogismo de porquê, como é patente no exemplo precedente. Pois, a causa da igualdade dos dois ângulos feitos sobre o espelho pelo raio incidente e refletido não é o termo médio tomado da geometria. Mas, sua causa é a natureza da radiação que se produz de acordo com o percurso reto e que, quando se produz sobre um obstáculo que tem em si a natureza do úmido espiritual, dá-se aí como princípio que a reproduz segundo um percurso semelhante àquele pelo qual se produz. Com efeito, sendo a operação da natureza finita e regular, é necessário que o percurso da reprodução seja semelhante ao percurso da sua produção. Assim, reproduz-se num ângulo igual ao ângulo incidente." 